\title{
Teoria Moral de Skinner e Desenvolvimento Humano
}

\author{
José Antônio Damásio Abib ${ }^{1}$ \\ Universidade Federal de São Carlos
}

\begin{abstract}
Resumo
Argumenta-se neste ensaio que Skinner adota um ponto de vista moral quando defende a sobrevivência das culturas como o último valor na ordem da descoberta e o primeiro na ordem da geração de valores derivados. Argumenta-se ainda que os valores derivados funcionam como critério de escolha de práticas culturais com o objetivo de promover o bem da cultura, isto é, sua sobrevivência. Com base nas críticas de Skinner e de autores pós-modernos redefine-se o conceito de desenvolvimento humano. Sugere-se que, como política de identidade pós-moderna, o conceito de desenvolvimento humano pode ser um valor para orientar práticas culturais com condições de promover a sobrevivência das culturas. Ou pode mesmo vir a ser o principal valor em uma cultura de direitos humanos.

Palavras-chave: Skinner; sobrevivência das culturas; moralidade; pós-moderno; desenvolvimento humano.
\end{abstract}

Skinner's Moral Theory and Human Development

\begin{abstract}
It is argued here that Skinner adopts a moral point of view when defending the survival of cultures as the ultimate value in the order of discovery and as the first value in the order of generation of derived values. It is also argued which derived values function as criterion of choice of cultural practices, with the objective of promoting "the good of the culture", that is, its survival. Based on Skinner's and post-modern writers' critique the concept of human development is defined anew. It is suggested that, as a post-modern policy of identity, the concept of human development may be a value for directing cultural practices capable of promoting the survival of cultures. Or it may even become the main value in a culture of human rights. Keywords: Skinner; survival of cultures; morality; postmodern; human development.
\end{abstract}

Skinner $(1971,1978,1989)$ defendeu a sobrevivência das culturas como o bem da cultura e referiu-se a várias conseqüências de práticas culturais - como superpopulação, poluição, devastação do meio ambiente e a possibilidade de holocausto nuclear - que ameaçam esse bem. Argumentou com base nessas conseqüências às quais ele também chama de razões - que a ciência e a tecnologia do comportamento podem contribuir para práticas culturais com a finalidade de defender o bem da cultura.

Skinner $(1971,1989)$ atribuiu a função de defender a sobrevivência das culturas ao planejador de uma cultura (the designer of a culture), que pode exercer sua função em uma comunidade utópica - como em Walden Two (Skinner, 1948) -, nas instituições de uma sociedade - ou, na parlance de Skinner, nas agências de controle, como, por exemplo, o governo, a religião, a educação, a economia e a indústria -, ou ainda em um "quarto estado" (fourth estate, Skinner, 1989, p. 120), constituído pela mídia, por professores,

\footnotetext{
${ }^{1}$ Endereço para correspondência:Universidade Federal de São Carlos, Departamento de Filosofia e Metodologia das Ciências. Via Washington Luiz, Km. 235, 13565-905, São Carlos, SP. Fone: (16) 2608366. E-mail: j.abib@zaz.com.br
}

cientistas e acadêmicos. Na verdade, Skinner (1989) revela uma simpatia por esse "quarto estado", porque é ele que apresenta condições de viabilizar não só um controle mais efetivo dos controladores mas também formas menos institucionalizadas de controle, como as relações de "controle pessoal face a face" (p. 120) descritas em Walden Two.

Desde espaços mais organizados (como os institucionais) até os menos organizados (como os das organizações da sociedade civil e das relações de controle pessoal face a face) o psicólogo está presente - e isso é importante porque é ele que, em princípio, deve ter o domínio da ciência e tecnologia do comportamento, com condições, portanto, de defender o bem da cultura. Ou seja, com o conceito de bem da cultura, Skinner (1971, 1978, 1989) sugere possibilidades viáveis de uma prática significativa para o psicólogo. Admitida a legitimidade e o valor desse discurso, revisita-se, aqui, alguns de seus conceitos cardeais.

Este ensaio examina, primeiro, o conceito de prática cultural em Skinner $(1971,1978)$ bem como algumas de suas sugestões sobre como modificar práticas culturais atuais com o objetivo de promover a sobrevivência das culturas sem que com isso ele se comprometa com o darwinismo social. Para acentuar a independência do 
conceito de prática cultural com relação ao darwinismo social e ao mesmo tempo apresentar mais uma razão a favor de práticas culturais com o propósito de promover o bem da cultura, será apresentada, em segundo lugar, a crítica de Skinner $(1971,1986,1990)$ ao conceito geral de desenvolvimento (das espécies, dos indivíduos e das culturas) e será argumentado que essa crítica bem como sua proposta de direcionalidade do desenvolvimento de culturas podem ser relacionadas não só com a crítica pósmoderna ao conceito de desenvolvimento humano mas também com a defesa de uma proposta alternativa para esse desenvolvimento (Hall, 1992/1998; Lyotard, 1979/ 1998, 1986/1987). Esse conceito pós-moderno de desenvolvimento humano pode não só se constituir em mais uma razão, mas talvez seja a mais importante na defesa de práticas culturais com condições de promover a sobrevivência das culturas. É evidente que apresentar razões para defender práticas culturais que promovem o bem da cultura é bem diferente de apresentar razões para defender o valor de sobrevivência das culturas. Por isso será examinado, em terceiro lugar, o que significa identificar a sobrevivência das culturas com o bem da cultura e se essa identificação fornece alguma razão para defender esse valor (Skinner, 1971).

Engajar-se em práticas visando ao desenvolvimento humano no contexto da crítica pós-moderna pode ser resumido, aqui, como uma prática cultural pós-moderna e por isso, finalmente, será brevemente argumentado que uma prática dessa natureza visando ao desenvolvimento humano exige a formação de pessoas com autocontrole e ao mesmo tempo criativas - conceitos esses que serão esclarecidos com base em Skinner (1953, 1968, 1974).

\section{Prática Cultural}

É possível agir para o próprio bem ou para o bem de outros. Porém, o que significa agir para o bem da cultura? Skinner (1971) afirma que é agir para a sobrevivência das culturas, e isso significa, no mínimo, proteger a cultura de práticas para ela letais como superpopulação, devastação do meio ambiente, poluição e a possibilidade de holocausto nuclear. Essa tese de Skinner tem dois fundamentos: seu conceito de bem ou valor e sua classificação do bem como bens pessoais, bens dos outros e o bem da cultura.

Duas características que definem o valor são o efeito das conseqüências do comportamento sobre o próprio comportamento e o sentimento que acompanha esse efeito. Como o efeito consiste no fortalecimento ou no enfraquecimento do comportamento, os sentimentos, grosso modo, polarizam-se, respectivamente, como positivos ou negativos. Conseqüências com efeitos fortalecedores e sentimentos positivos são boas e conseqüências com efeitos enfraquecedores e sentimentos negativos são más, ou seja, são valoradas como boas ou más. As conseqüências fortalecedoras são reforçadoras (e por isso são positivas) e as conseqüências enfraquecedoras são punitivas (e por isso são negativas) e, sendo assim, o valor bom refere-se a conseqüências reforçadoras e sentimentos positivos e o valor mau a conseqüências punitivas e sentimentos negativos. Conseqüências reforçadoras fortalecem o comportamento que as produz (sua presença é boa) e enfraquecem o comportamento que as remove (sua ausência é má): são os reforçadores positivos. Conseqüências punitivas enfraquecem o comportamento que as produz e fortalecem o comportamento que as remove, sua presença é má e sua ausência é boa: são os reforçadores negativos. Logo, boa é a presença do reforçador positivo, a ausência do reforçador negativo e a presença dos sentimentos positivos que os acompanham; e má é a ausência do reforçador positivo, a presença do reforçador negativo e a presença dos sentimentos negativos que os acompanham. Assim como a polaridade positiva e negativa das conseqüências do comportamento é passível de uma análise mais detalhada quando se examinam as relações temporais entre o comportamento e suas conseqüências, a polaridade positiva e negativa dos sentimentos também é suscetível de um maior esclarecimento quando se verificam as relações entre os sentimentos e o tipo, a intensidade e o contexto das conseqüências. Por exemplo, se a conseqüência é um reforçador positivo, o sentimento é de confiança; se é uma punição velada e branda, é de vergonha; se é uma punição explícita e intensa, é de culpa; se o contexto muda de familiar para estranho (onde comportamentos apropriados ao primeiro não são necessariamente adequados ao segundo), o sentimento é de nostalgia (Skinner, 1974). Em suma, é com base no efeito das conseqüências do comportamento e nos sentimentos que o acompanham que os indivíduos formulam juízos de valor ou atribuem valor às coisas.

A classificação do bem em bens pessoais e bens dos outros recebe seu esclarecimento inicial com a diferença entre reforçadores primário e condicionado. Ao longo da evolução das espécies elaborou-se a suscetibilidade dos organismos às conseqüências do comportamento e essa disposição genética, constituída pela história filogenética, está na base da explicação da história do indivíduo ou da história ontogenética do comportamento (Skinner, 1969, 1971, 1974). Com efeito, é por causa dessa suscetibilidade que comportamentos podem ser reforçados por água, alimento, sexo e fuga de predadores, ou punidos por agressão e danos físicos provenientes de 
predadores. Essas conseqüências reforçadoras e punitivas, por sua presença ou remoção e que encontram a explicação de seu poder de funcionamento na natureza, são os reforçadores primários. Sinais desses eventos, como a presença de uma fêmea ou de um predador, fortalecem, por sua relação final com sexo ou danos físicos, os comportamentos preliminares que conduzem à presença da fêmea ou que evitam a presença do predador - são reforçadores derivados de reforçadores primários, como sexo, água, alimento, remoção de danos físicos, e por isso são chamados de reforçadores condicionados. A cultura humana está repleta desses reforçadores como, por exemplo, a atenção, o elogio, a aprovação, o apreço, o aplauso, o prêmio, a condecoração, o dinheiro, o prestígio, a submissão oferecida por pessoas, a posse de propriedades, a censura, a desaprovação, a ameaça, o castigo.

Ao participar de uma relação social o indivíduo se comporta visando dois bens, o seu e o de outros. Uma pessoa libera reforçadores condicionados positivos para outras e vice-versa. No momento oportuno elas trocam esses reforçadores por reforçadores condicionados mais básicos ou por reforçadores primários positivos. Por exemplo, o patrão transforma o produto do trabalho de seu empregado em dinheiro e remunera-lhe pelo serviço prestado; oportunamente ambos compram roupas, remédios, alimentos. Os complexos reforçadores condicionados da vida social funcionam como mediadores entre o comportamento e reforçadores condicionados mais básicos e só reforçam porque, em última análise, podem ser trocados por reforçadores primários. E esses, por sua vez, só têm valor por causa da suscetibilidade dos indivíduos às conseqüências do comportamento. É por isso que quando o indivíduo se comporta visando o bem de outros, visa também, intencionalmente ou não, seu próprio bem. Esses dois tipos de valores (os bens pessoais e os bens dos outros) - na medida em que se referem à reprodução, manutenção da vida e até mesmo à liberdade para preservar a integridade física correspondem, por assim dizer, à ordem vital ou à defesa da vida e da liberdade. Seria tolice negar a importância desses valores para os indivíduos, pessoas e relações sociais; contudo, surgem dificuldades no prolongamento dessa ordem vital na cultura, que podem ser enfrentadas com práticas culturais visando à sobrevivência das culturas (Skinner, 1971, 1978).

A natureza prolonga-se na cultura com base nas disposições genéticas dos humanos. Na história filogenética as conseqüências imediatas do comportamento tiveram maior valor de sobrevivência e por isso foram mais efetivas do que conseqüências atrasadas ou proteladas. Por causa dessa história, os humanos, como outras criaturas, tornaram-se sensíveis ao reforçamento advindo de conseqüências imediatas. Essa herança está na origem de práticas culturais que se constituem ao mesmo tempo em graves problemas para as culturas humanas. Algumas práticas culturais produzem conseqüências desfavoráveis como violência, superpopulação, obesidade, alcoolismo, tabagismo, dependência de drogas e outras coisas do gênero. Práticas culturais que geram violência, superpopulação e obesidade relacionam-se com conseqüências reforçadoras fundamentadas em práticas naturais como danos ao predador, sexo, e alimento; outras, que produzem alcoolismo, tabagismo e dependência de drogas, relacionam-se com conseqüências reforçadoras que não tiveram qualquer valor de sobrevivência na história evolutiva da espécie humana. No entanto, todas essas práticas culturais geram conseqüências reforçadoras imediatas e punição retardada, atrasada. Ou seja, para fortalecer e manter essas práticas não importa se as conseqüências reforçadoras são naturais ou não; para que funcionem basta que sejam imediatas, porque essa é a condição mínima estabelecida pela natureza. Outra prática disseminada nas culturas ocidentais é o uso da punição. Novamente, a explicação para essa prática altamente nociva às culturas - seja porque promove ódios e ressentimentos, seja porque gera mais violência encontra-se na imediaticidade da natureza humana. Com efeito, a punição gera para o agente punidor reforços mais imediatos do que aqueles que poderiam advir do uso de reforços positivos. Por exemplo, pais e professores são imediatamente reforçados pelo enfraquecimento ou remoção ao menos temporária dos comportamentos de filhos e alunos, que eles punem porque os acham inadequados ou errados. Mais difícil é usar reforço positivo para comportamentos adequados e corretos. Identificálos e ensiná-los é freqüentemente complexo e demorado. Isso pode dificultar mas não impede que pais e professores sejam bem sucedidos na tarefa de identificar e ensinar comportamentos adequados e corretos. Pais e professores bem sucedidos recebem reforço positivo por seus comportamentos. Mas no caso que está sendo descrito, o reforço é atrasado. E reforço atrasado tende a ser menos efetivo do que reforço imediato. Ou seja, reforço e punição funcionam se são imediatos, mas não se são atrasados. Essas práticas fornecem, portanto, boas evidências para o imediatismo da natureza. A cultura é em parte um prolongamento da natureza e muito de suas práticas transformam-se em problemas porque comportamentos verificados nessas práticas perderam o valor de sobrevivência que tinham na natureza e em 
condições culturais adversas. O óbvio valor de sobrevivência do comportamento sexual, agressivo e alimentar, não só na natureza, mas também em condições culturais adversas - como na fome, nas doenças, guerras e nos ambientes perigosos (como é o caso também em muitas culturas atuais) - dificilmente pode ser subestimado. Porém, em princípio, as culturas representam ambientes ou contextos qualitativamente diferentes dos que são encontrados na natureza. O domínio técnico-científico da natureza com a conseqüente produção de riqueza bem como a evolução de formas democráticas de governo propiciam ao gênero humano a oportunidade de controlar as condições que, por exemplo, geram doenças, superpopulação e violência. Ou seja, é possível não somente circunscrever os problemas gerados por práticas culturais que são, em parte, prolongamentos da natureza, mas também, eventualmente, encaminhar propostas de solução. O imediatismo da natureza e as práticas culturais que revigoram esse imediatismo, perpetuando-o num contexto que lhe é cada vez mais estranho, representam obstáculos poderosos para as culturas. É por isso que stricto sensu o conceito de prática cultural, isto é, o conjunto de práticas culturais que definem uma cultura, é, de um lado, controle da natureza e, de outro, invenção de práticas jamais vistas na natureza.

\section{Modificação e Propostas de Práticas Culturais}

Engajar-se no bem da cultura significa enfrentar essa suscetibilidade e promover práticas culturais com condições de tornar mais efetivas as conseqüências remotas do comportamento. Ou seja, práticas que ameaçam a sobrevivência das culturas - que produzem reforço positivo imediato com conseqüências negativas postergadas, como as que foram descritas por Skinner (1971) - precisam ser enfrentadas com modificação das contingências, programando-se conseqüências negativas mais imediatas para essas práticas ou fortalecendo-se práticas alternativas com condições de substituí-las. O modelo do controle do comportamento aplicado a casos como os do tabagismo, alcoolismo, vício em drogas e obesidade explica bem a lógica dos conceitos comportamentais envolvida na mudança de práticas culturais.

Todos esses casos implicam conseqüências reforçadoras imediatas e conseqüências negativas postergadas. Skinner (1989) analisa o caso do tabagismo e sugere que ele serve como um "modelo em miniatura" (p. 118) para ensinar o que pode ser feito em relação às práticas culturais. Primeiro, o cigarro envolve dois reforçadores imediatos, um positivo e outro negativo, o primeiro produz "prazer" e o segundo "alívio" de sintomas. Segundo, é punitivo, produz conseqüências negativas postergadas, como, por exemplo, o câncer de pulmão. Terceiro, punições postergadas, como câncer de pulmão, são inefetivas pelo simples fato de que ainda não ocorreram - conseqüentemente, conselhos que apelam para razões desse tipo não funcionam. Quarto, é possível programar conseqüências aversivas mais imediatas como taxar pesadamente o cigarro, restringir os locais para fumantes, etc. Finalmente, pode-se reforçar positivamente fumantes por não fumar ou elogiar com grande entusiasmo os que pararam de fumar.

Com base nesse "modelo em miniatura", Skinner (1989) sugere que em uma escala muito maior pode-se argumentar com as pessoas para: "[1] ter poucos filhos ou nenhum (...). [2] Promover formas de vida com menos consumo e poluição. [3] Reduzir a agressão e a probabilidade de guerra com uma melhor distribuição da riqueza do mundo" (p. 118).

Se essa sugestão de Skinner (1989) parece simplificar demasiadamente as coisas, deve-se manter presente que ele recorre não só ao modelo apresentado acima mas também a uma extensa literatura sobre utopias, desde $A$ República até Walden Two, para refletir sobre o planejamento cultural. O argumento geral de Skinner (1971) para recorrer ao pensamento utópico baseia-se em sua afirmação básica de que planejar uma cultura é como planejar um experimento e é a idéia de um experimento que orienta as utopias - é por isso que normalmente elas são pequenas, isoladas, desinstitucionalizadas e internamente coerentes. Como as utopias, modelos de controle do comportamento são também como experimentos, e por isso podem ser utilizados para auxiliar no planejamento cultural. $\mathrm{Na}$ verdade, a diferença entre o experimento na ciência e o experimento nas utopias, nos modelos de controle do comportamento e no planejamento cultural é a diferença entre verificar o que acontece e verificar se o planejamento funciona, ou seja, é a diferença entre ciência e tecnologia. Em suma, Skinner $(1971,1989)$ recorre a modelos em miniatura e a utopias para refletir sobre a lógica do planejamento cultural - vale-se, portanto, de modelos ideais, que como tal são suscetíveis de ajustes na fase de aplicação, mantendo-se, no entanto, a validade geral de seus princípios.

Como se observa no modelo em miniatura, Skinner (1989) refere-se não somente ao controle de práticas prejudiciais mas também ao reforçamento daquelas que são favoráveis aos indivíduos e às culturas. Ou seja, é necessário descobrir, inventar e fortalecer práticas que promovam a sobrevivência dos indivíduos e das culturas. Essa observação tem seu valor porque 
usualmente o conceito de sobrevivência vem acompanhado da noção de práticas competitivas entre culturas ou entre pessoas e grupos no interior de culturas, sugerindo compromissos com o darwinismo social, como é reconhecido por Skinner (1978): "Provavelmente rejeitaremos a sobrevivência como um valor porque ela sugere competição com outras culturas, como no darwinismo social, onde o comportamento agressivo é exaltado" (p. 197). Sugere então outras práticas culturais: "Mas outras contingências de sobrevivência são importantes, e o valor da cooperação e do comportamento de apoio pode ser facilmente demonstrado" (p. 197). A questão central, portanto, resume-se no engajamento em práticas de sobrevivência cultural capazes de competir com práticas mortais para as culturas. Ou seja, a competição não é entre pessoas, grupos e culturas, mas entre práticas de sobrevivência e práticas letais para uma cultura. Por exemplo, se a violência assume proporções letais para uma cultura, então práticas com condições de competir e controlar a violência, reduzindo-a a níveis toleráveis, contribuirão para promover a sobrevivência das culturas. Práticas de sobrevivência cultural referem-se então a práticas que contribuem para construir uma cultura mais pacífica, e os que se engajam nessas práticas visam o pacifismo. E se uma violência intolerável aflige várias culturas, engajarse na sobrevivência de todas elas por um pacifismo universal significa, por um lado, promover cooperação, solidariedade e apoio; e por outro, desestimular a competição.

Enfim, defender o pacifismo é engajar-se em práticas que promovem a sobrevivência das culturas como cooperação, apoio, solidariedade, tolerância, compaixão (Skinner, 1971, 1974, 1978). Na verdade, o pacifismo é uma das razões que podem promover a sobrevivência das culturas. Há outras?

\section{Desenvolvimento Humano}

Skinner (1971) critica o conceito de desenvolvimento como evolução direcionada à perfeição de espécies, indivíduos e culturas. Nesse conceito, evolução significa mudança temporalmente seqüenciada de formas ou estruturas, o que equivale a dizer que as espécies, os indivíduos e as culturas avançam por estágios e que as formas posteriores originam-se das anteriores. $\mathrm{O}$ aspecto direcional da evolução significa que há um princípio predeterminando o desdobrar de uma seqüência fixa de estruturas e que esse princípio é a perfeição. Portanto, incorpora-se na direcionalidade evolutiva a metáfora do crescimento para a perfeição, que é vista como maturidade. É essa metáfora com fundamentos botânicos que legitima expressões como estágios fixos de desenvolvimento, crescimento, progresso, maturidade e perfeição - expressões que Skinner não aceita.

A crítica de Skinner (1971) refere-se à duas concepções que fundamentam esse conceito de desenvolvimento. A primeira é o estruturalismo, que aposta no tempo como fator fundamental para a evolução de formas e simultaneamente ignora os acontecimentos que ocorrem no tempo. Dizendo mais tecnicamente, o estruturalismo ignora as contingências de reforço positivo e negativo. A segunda é a doutrina metafísica do evolucionismo, que defende a natureza progressiva de todos os aspectos da realidade (do universo, da terra, da sociedade, do governo, da indústria, das ciências, das artes); um progresso que vai do simples ao complexo por diferenciações sucessivas, e que no caso da vida humana tende não só à perfeição mas também à felicidade.

Skinner (1971) defende que não só a velocidade mas também a ordem de estágios de desenvolvimento de crianças, de indivíduos e de culturas dependem das contingências de reforço e que não tem sentido argumentar que o amadurecimento do indivíduo seja algo desejável em toda sua extensão. Passando-lhe a palavra: "Ninguém está ansioso para "tornar-se" [become] senil, a pessoa madura gostaria de ter o seu desenvolvimento interrompido ou estabilizado; daquele ponto em diante ela não se importaria de ser um retardado” (p. 141). E logo a seguir ele comenta que há um xenofobismo quando, com base no conceito de maturidade, diferenciam-se culturas "desenvolvidas" de culturas "subdesenvolvidas". Com efeito, "chamamos algumas culturas subdesenvolvidas ou imaturas em contraste com outras que chamamos "avançadas". Mas trata-se de uma forma grosseira de xenofobismo [j̈̈noism] querer dizer com isso que qualquer sistema econômico, de governo ou religião [das culturas "avançadas"] é maduro" (pp. 141-142).

Skinner (1971) desvincula a metáfora do crescimento dos conceitos de evolução e direção evolutiva. Seja no caso das espécies ou das culturas, não aceita a metáfora do crescimento ou a idéia darwinista de desenvolvimento para a perfeição, porque em ambos os casos pode-se constatar o mau êxito (é o caso de espécies e culturas extintas). Skinner aceita porém a idéia de que a evolução das espécies, dos indivíduos e das culturas tem uma direção: por exemplo, o aparecimento de estruturas mais complexas, uma maior sensibilidade a estímulos, uma utilização mais efetiva de energia e, principalmente, a progressiva sensibilidade dos organismos e das pessoas às conseqüências de suas ações. O importante, nesse momento, é enfatizar que, embora essa progressiva 
sensibilidade não signifique evolução dirigida à perfeição, ela é fundamental porque é ela que torna possível o engajamento de indivíduos no bem da cultura.

Esse aspecto positivo do conceito de desenvolvimento defendido por Skinner (1971) pode ser importante para elaborações pós-modernas desse conceito, como será sugerido adiante. No entanto, cabe observar ainda que Skinner $(1986,1990)$ aprofundou sua crítica ao conceito de desenvolvimento quando teceu comentários sobre as sociedades capitalistas dos países desenvolvidos. Com o objetivo de ampliar as similaridades entre a crítica de Skinner $(1971,1986,1990)$ e a crítica pós-moderna ao conceito de desenvolvimento e desse modo estabelecer a lógica da transição para a crítica pós-moderna, cabe, aqui, dizer o seguinte: Primeiro, Skinner (1986) afirma que "o Ocidente perdeu sua inclinação para agir" (p. 572). Isso significa dizer que, como na maioria das vezes o comportamento das pessoas em vez de ser modelado por contingências é governado por regras, elas não têm experiência direta nem com os comportamentos, nem com as situações, nem com as conseqüências de suas ações. As pessoas desenvolvem então uma relação de estranhamento com o seu mundo, um mundo onde a experiência com a produção pessoal de bens culturais é substituída meramente por seu consumo. Daí, elas "só podem relaxar com a ajuda de sedativos ou tranqüilizantes (...) ou só podem dormir com ajuda de soníferos ..." (Skinner, 1986, p. 573). Segundo, Skinner (1990) afirma que as várias culturas existentes são conflitantes e contudo "uma cultura prepara um grupo somente para o mundo que se assemelhe ao mundo em que a cultura evoluiu" (p. 1207). Ou seja, as sociedades desenvolvidas ou maduras estão formando pessoas alienadas de seu mundo e incapazes ao mesmo tempo de compreender outros mundos. Há, portanto, a necessidade de uma formação que resgate a experiência direta e a experiência com a diversidade de culturas ou de mundos. É com base nisso que será apresentada a seguir não só a crítica mas também uma alternativa pós-moderna ao conceito de desenvolvimento

O conceito de desenvolvimento remonta a Aristóteles (s.d./1985a), mas foi apenas por ocasião da Revolução Francesa e na filosofia das Luzes que ele passou a significar crença no progresso e na emancipação da humanidade (Abbagnano, 1962/1982; Lyotard, 1979/1998, 1986/ 1987). Esse conceito governou o pensamento e a ação dos séculos XIX e XX com resultados melancólicos e contraditórios (Lyotard, 1986/1987). Na verdade, isso ocorreu porque se, por um lado, esse conceito comprometeu-se com filosofias otimistas da história, da sociedade e da ciência, como as doutrinas metafísicas do evolucionismo e do romantismo; por outro lado, vinculou-se também com a defesa de práticas sociais tradicionalistas e nacionalistas (Abbagnano). Embora a filosofia do século XX não tenha conseguido se libertar inteiramente dessas idéias, o que se verifica é uma ruína gradativa desse otimismo (Abbagnano).

O ceticismo diante da idéia de emancipação da humanidade concentra-se nas tantas promessas não realizadas do discurso moderno como, por exemplo, a de que com o desenvolvimento da razão os seres humanos atingiriam a maioridade e com o progresso científico, técnico, político, moral e social criariam abundância e justiça (Lyotard, 1979/1998).

Foi exatamente o desenvolvimento e não a sua ausência que possibilitou guerras mundiais, totalitarismos, a riqueza do Norte e a pobreza do Sul, o neo-analfabetismo, a desculturação produzida pela crise da escola, o desemprego, o despotismo da opinião e dos preconceitos reproduzidos pela mídia e o subdesenvolvimento. É por isso que a esse desenvolvimento "já não ousamos chamarlhe progresso" (Lyotard, 1986/1987, p. 115).

Adorno (1971/1995) escreveu sobre o que e para que poderia ser a educação após Auschwitz, e defendeu entre outras coisas a necessidade inadiável de modificar as condições que conduzem à barbárie; e Lyotard (1986/ 1987) redigiu: "Depois de Theodor Adorno, usei o termo 'Auschwitz' para significar quanto a matéria da história ocidental recente parece inconsistente relativamente ao projeto 'moderno' de emancipação da humanidade" (p. 95). Lyotard admite que sua incredulidade contém uma mágoa, é a mágoa da promessa que não foi cumprida, não porque foi esquecida e sim por causa do próprio desenvolvimento.

Uma sociedade que ao cumprir sua promessa de emancipação produz um desenvolvimento humano que fracassa em seu propósito necessita diagnosticar seus erros e tentar corrigi-los. Em outras palavras, a questão do desenvolvimento humano tem de ser repensada em outras bases.

Atualmente, com o advento da filosofia pós-empirista da ciência, da crítica pós-moderna e da cultura pósfilosófica, a universalidade, objetividade e certeza do conhecimento tornaram-se profundamente questionáveis, seja da perspectiva de uma realidade que existe em si ou de uma realidade constituída por uma subjetividade transcendental, universal (Bernstein, 1983; Rorty, 1980, 1994/1997). Sendo assim, objetivismo, subjetivismo (no sentido de subjetividade transcendental) e universalismo são temas e conceitos em baixa, e o relativismo ganha fôlego. Isso, de um lado; porque, de outro lado, existe também o esforço de ultrapassar ou esvaziar as dicotomias que podem ser constituídas por esses temas como, por 
exemplo, objetivismo-subjetivismo, objetivismorelativismo e universalismo-relativismo (Bernstein, 1983; Polkinghorne, 1989; Rorty, 1982).

Essas reflexões mais recentes recortam um cenário mais propício para se repensar a questão do desenvolvimento humano. Com efeito, não existe a realidade, a verdade, a certeza. Existem realidades, verdades, certezas. Mas, como não se trata também de defender o relativismo, os significados das realidades, verdades e certezas devem ser conversados e argumentados. Em uma palavra, devem ser negociados (Bruner, 1986, 1990).

A existência de diferenças de épocas históricas, culturas e sociedades humanas já foram plenamente demonstradas pela história, antropologia e sociologia e são elas que fornecem a premissa fundamental para se repensar o conceito de desenvolvimento humano. Com seus compromissos anteriores no modernismo, o conceito de desenvolvimento humano enfatizava semelhanças. Agora, a ênfase é colocada nas diferenças, na paralogia ou no investimento e na realização de dissensos (Lyotard, 1979/ 1998). As semelhanças perdem sentido, sendo substituídas por consensos locais e efêmeros, envolvem, portanto, participantes atuais e podem, por isso, ser modificados a qualquer momento. Representam, enfim, um estágio das discussões e não um acordo final e universal (Lyotard, 1986/1987).

Trata-se então de desenvolvimento humano de diferenças e, como tal, diferenças humanas de um padrão qualquer não significam deficits, deficiências, mas, isto sim, possibilidades de desenvolvimento de outras formas de vida cultural, política, social e moral, ou seja, de desenvolvimento de uma política de identidade que vê nas diferenças o espaço de construção de identidades (Hall, 1992/1998).

A política de identidade surgiu com o movimento feminista e desde então passou a referir-se a movimentos sociais que lutam para defender suas identidades, como no caso, por exemplo, da política de gênero do feminismo, da política antibelicista de pacifistas, da política sexual de gays e lésbicas, da política ambientalista de ecologistas, da política de grupos perseguidos ou excluídos por sua cor ou por suas crenças religiosas, etc. Essa política e esses movimentos já existiam antes da crítica pós-moderna ou da modernidade tardia, mas foi somente com o adensamento dessa crítica que se revestiram da preeminência e significado atual, ou seja, foi necessário que se demonstrasse a falência dos procedimentos da sociedade política para defender, respeitar e conviver com os direitos dos excluídos ou direitos de diferenças de identidade (Hall, 1992/1998).
Uma política de identidade dessa natureza é antiterrorista porque não tenta no caso de dissenso obter o consentimento de um parceiro com a ameaça de exclú́lo do jogo de linguagem que se joga. É exatamente essa ameaça que está presente no terror: "Ele se calará ou dará seu assentimento não porque (...) é refutado, mas [porque é] ameaçado de ser privado de jogar" (Lyotard, 1979/1998, p. 115).

A política de identidade constitui-se em uma alternativa pós-moderna ao conceito moderno de desenvolvimento bem como em uma razão tão forte quanto o pacifismo (se não mais, na medida em que parece ser uma condição para o pacifismo) para defender práticas de sobrevivência cultural como apoio, cooperação, solidariedade, tolerância e compaixão. Mas, razões para defender essas práticas não devem ser confundidas com as eventuais razões para defender o valor de sobrevivência das culturas, ele mesmo.

\section{Sobrevivência das Culturas e Moralidade}

Pode-se interpretar a defesa do valor de sobrevivência das culturas por Skinner $(1971,1978)$ como a escolha de um bem com condições de controlar as tendências imediatistas da natureza e de ensinar os indivíduos a esperarem por conseqüências positivas postergadas - duas condições necessárias para definir e salvar as culturas. $\mathrm{O}$ valor de sobrevivência das culturas tem condições de realizar esse objetivo porque refere-se ao futuro, a um tempo, portanto, que está bem além do tempo de vida do indivíduo (é importante notar que Skinner acha que o presente das culturas encontra-se ameaçado); sendo assim, não pode funcionar como reforçador condicionado ou como um mediador entre os comportamentos que promovem a sobrevivência das culturas e reforçadores primários pelos quais poderia ser trocado. Ou seja, não é um reforçador condicionado e, conseqüentemente, não pode ser trocado por bens pessoais. Obviamente, o valor de sobrevivência das culturas não é também um reforçador primário. Logo, se o indivíduo se comporta em função de uma conseqüência que não vai usufruir e que não é um reforçador primário ou um reforçador condicionado, então deixam a cena o imediatismo da natureza e as ações em defesa de bens pessoais. Em suma, o valor de sobrevivência das culturas não se inscreve na ordem vital dos bens pessoais e dos bens dos outros: é um bem da cultura e trata-se, portanto, de um valor que pode "não ter desempenhado qualquer papel na evolução física das espécies" (Skinner, 1971, p. 143).

Sem justificativa natural, o valor de sobrevivência das culturas implica a possibilidade de conseqüências reforçadoras sem fundamento na ordem vital. São várias 
as evidências a favor dessa possibilidade. Primeiro, as conseqüências reforçadoras no alcoolismo, tabagismo e na dependência de drogas não podem ser explicadas com base em qualquer valor de sobrevivência na história evolutiva da espécie humana (Skinner, 1971). Segundo, práticas culturais como, por exemplo, a violência e a gula, têm seu início na suscetibilidade das pessoas a reforçamentos primários e condicionados; mas não podem ser explicadas pela natureza. Com efeito, o glamour da culinária nacional, internacional e dos cardápios, da violência televisiva e cinematográfica remete a conseqüências de ordem sociológica e psicológica que atribuem uma qualidade especificamente humana à violência e à gula, que é completamente desconhecida das criaturas que comem e agridem apenas para sobreviver bem como não cozinham iguarias nem fazem guerras para vender armas ou vencer eleições. Terceiro, não parece haver qualquer justificativa natural para o valor estético da obra de arte, por exemplo, o que na natureza explicaria a fruição incansável da paixão de uma peça de Rachmaninov? O valor de sobrevivência das culturas só vem fortalecer a noção de que a característica básica de reforçadores é seu poder de fortalecer o comportamento, onde reforçadores naturais e derivados representam tão somente um caso específico. É nesse sentido que solicitar razões para a defesa do valor de sobrevivência só tem, nas palavras de Skinner, uma resposta honesta: "Não há nenhuma boa razão (...), mas se sua cultura não o convenceu de que há, tanto pior para ela" (p. 137).

Pode-se aprofundar essa análise perguntando-se o que significa a expressão bem da cultura - uma questão pertinente, porque usualmente fala-se em bens de pessoas, indivíduos. Com efeito, bem da cultura parece personificar uma entidade independente à qual os indivíduos deveriam expressar zelo e devoção. Porém, não se trata disso. Skinner (1971) dá uma pista não só quando pergunta por que pessoas vivendo no final do século XX deveriam se preocupar com as condições de vida de pessoas vivendo no final do século XXI mas também quando afirma que o planejamento de uma cultura deve ir "além dos interesses imediatos do controlador e do controlado" (1978, p. 197). Ou seja, o bem da cultura, como o bem dos outros, refere-se também aos outros, com esta diferença: são os outros do futuro, nossos filhos e nossos netos e os filhos e netos dos outros que são nossos contemporâneos. Esclarecido que o bem da cultura é o bem das pessoas do futuro torna-se evidente que engajarse na defesa da sobrevivência das culturas é engajar-se na defesa da sobrevivência das pessoas do futuro.

Com o valor de sobrevivência das culturas, Skinner $(1971,1978)$ adota definitivamente o ponto de vista moral e evita reduzir a moralidade à prudência ou o bem moral ao bem prudencial. O ponto de vista prudencial é associado com o egoísmo ético e é conflitante com a moralidade (Frankena, 1963; Garrett, 1979). De acordo com o egoísmo ético, as pessoas colocam os interesses privados acima dos públicos e mesmo quando agem em prol dos últimos só o fazem por motivos pessoais, ou seja, na melhor das hipóteses todo altruísmo é interessado (Frankena). Skinner (1971) defende um equilíbrio entre os bens pessoais (interesses privados) e os bens dos outros (interesse público). Na verdade, é esse equilíbrio que ele chama de justiça. Com esse conceito, Skinner (1971) evita o pior tipo de egoísmo ético - aquele que sequer respeita o interesse público - bem como condena dois tipos de conseqüências resultantes do desequilíbrio entre os interesses públicos e privados. Ele comenta que, quando as agências de controle desequilibram além de limites suportáveis e a seu favor a relação entre os bens pessoais obtidos pelo indivíduo e os bens que elas recebem, o indivíduo busca refúgio em reforçadores imediatos e torna-se amoral, anômico, vazio, incapaz de sentir prazer, desamparado, excluído, descrente e sem ideais para defender, descambando para um individualismo tão condenável quanto o sistema explorador (exploitative system) que o conduziu a essa condição.

Segundo Skinner (1971), justiça significa então evitar o egoísmo ético completamente alienado do interesse público, o individualismo e o sistema explorador. Mas, aparentemente, deixa subentendido que não é incompatível com o altruísmo interessado. Sendo assim, o conceito skinneriano de justiça implica o ponto de vista prudencial, o que o expõe à crítica, porque se, por um lado, é um conceito com os méritos de evitar o individualismo e os sistemas opressivos, por outro lado, parece colocar-se na contramão da moralidade. Esse ponto é, no entanto, discutível na exata medida em que desde a Antigüidade cogitou-se da possibilidade de se constituir o ponto de vista moral levando-se em conta as motivações humanas e que na cultura pós-filosófica procura-se compatibilizar prudência com moralidade (Abbagnano, 1962/1982; Aristóteles, s.d./1985b; Frankena, 1963; Platão, s.d./1985; Rorty, 1994/1997).

Se Skinner (1971) houvesse concluído sua discussão sobre o ponto de vista moral buscando um equilíbrio entre bens pessoais e os bens dos outros, sua posição já seria interessante da perspectiva daqueles que buscam na cultura pós-filosófica, como Rorty (1994/1997), compatibilizar prudência com moralidade. No entanto, Skinner observa que sua reflexão com base apenas nesses dois valores ficaria incompleta - especialmente para justificar porque alguém deveria se preocupar com 
valores como justiça - se não considerasse o valor de sobrevivência das culturas. Com efeito, porque é com esse valor que ele, como já foi dito, adota definitivamente o ponto de vista moral. E por quê? Porque é com esse valor que os interesses dos controladores e dos controlados do presente são neutralizados - interesses que beneficiam tão somente eles mesmos. Ou seja, com ele, ninguém visa bens pessoais ou interesses privados, a ação de todos dirige-se para as pessoas que viverão no futuro. Skinner abandona, portanto, qualquer compromisso com o ponto de vista prudencial e, por implicação, pode-se dizer que passa a defender o altruísmo puro. Sem dúvida trata-se de uma obrigação que exige autocontrole, porque a sobrevivência das culturas é uma conseqüência provavelmente muito remota para que os que se esforçam por ela possam desfrutá-la. Pode, no entanto, contribuir para esse esforço ou para esse autocontrole a direcionalidade do desenvolvimento humano que, como defendeu Skinner, tem acentuado a progressiva sensibilidade das pessoas às conseqüências de suas ações e isso significa o aprimoramento da capacidade de esperar por conseqüências reforçadoras remotas, tão remotas que talvez não se viva o suficiente para usufruí-las. Um espírito cético, pós-filosófico ou pós-moderno pode ainda perguntar: Afinal, por que devo me instalar em um ponto de vista absolutamente moral e defender, por exemplo, um altruísmo puro? A resposta poderia ser esta: A ciência não pode mesmo fundamentar a ética do altruísmo puro (na verdade, talvez não possa fundamentar qualquer tipo de ética); e há alternativas, como, por exemplo, o egoísmo desmedido no estado de natureza, o altruísmo interessado, o Estado-Leviatã e o individualismo (Dawkins, 1976/1989; Frankena, 1963; Hobbes, 1651/ 1983; Skinner, 1971).

\section{Conclusão}

Skinner (1971) defende que a ciência e a tecnologia do comportamento são importantes para o engajamento em práticas culturais bem como em suas modificações e desenvolve uma ampla discussão do conceito de prática cultural no contexto da ética. Isso faz sentido, especialmente quando se recupera as distinções aristotélicas entre ciência (theoria), técnica (poiesis) e prática (praxis) onde técnica refere-se a um tipo de ação, a um fažer, cujas conseqüências não remetem a qualquer envolvimento do agente seja com sua própria ação ou com suas conseqüências, e onde prática refere-se a um outro tipo de ação, a um agir, cujas conseqüências remetem a um envolvimento do agente tanto com sua própria ação quanto com as suas conseqüências, que é precisamente o caso da ética e da política, onde a ética consiste na introdução à política (Aristóteles, s.d./1985b). Esse breve paralelo entre Skinner e Aristóteles pretende apenas salientar as diferenças entre os conceitos de prática e técnica, mas não deve ser levado muito longe porque as diferenças podem ser importantes, por exemplo, para Skinner, a técnica é condição para a prática - uma relação que não se encontra em Aristóteles. Deve ser enfatizado, contudo, que para ambos os pensadores a prática referese à ética e se para o pensador grego a ética é a introdução à política, não deixa de ser sugestivo dessa perspectiva situar a ética de Skinner como uma introdução a seu pensamento político, e seria interessante investigar o desenvolvimento desse pensamento.

O primeiro valor ético na ordem da geração e o último na ordem da investigação defendido por Skinner (1971, 1978, 1989) é a sobrevivência das culturas. É esse o bem ou valor moral que, em última análise, explica quais são as conseqüências, as razões ou os valores derivados que devem servir como critérios para a escolha de práticas de sobrevivência das culturas. Ou seja, o primeiro e último bem ou valor ético é aquele que se instala na moralidade e os bens ou valores derivados são os meios ou instrumentos aos quais se recorre para escolher práticas com condições de realizar aquele bem básico, principal, último e primeiro. Aparentemente, na categoria de valores instrumentais defendidos por Skinner (1971, 1974, 1978, 1989) estão: conhecimento, habilidades, tolerância, cooperação, apoio, compaixão, justiça, paz, ordem, segurança, preservação do meio ambiente, abundância. Esses são, então, valores que devem orientar a escolha de práticas de sobrevivência das culturas. Um outro valor derivado que pode, no contexto dos valores derivados, ser um dos mais básicos é o desenvolvimento humano, um bem que pode ser elaborado com base nas críticas de Skinner e de pensadores pós-modernos bem como em sua sugestão sobre a direcionalidade do desenvolvimento humano e também em propostas pósmodernas de desenvolvimento humano. Resumidamente, no contexto da crítica pós-moderna, esse conceito consiste em uma progressiva sensibilidade das pessoas às conseqüências de suas ações referentes a uma política de identidade, ou seja, refere-se a uma estreita relação entre ética e política, o que não deixa de lembrar a tese de Aristóteles relativa à ética como introdução à política.

É importante ressaltar, porém, que não há nenhuma necessidade lógica obrigando a política de identidade a subordinar-se como valor derivado à sobrevivência das culturas como valor principal. Ou seja, o desenvolvimento humano como política de identidade pode perfeitamente ser desvinculado dessa relação de subordinação e ser 
assumido como valor principal, como na cultura de direitos humanos defendida por Rorty (1994/1997): “O melhor sinal de nosso progresso em direção a uma cultura de direitos humanos plenamente realizada pode ser a medida em que deixamos de interferir nos planos matrimoniais de nossos filhos em função da origem nacional, religião, raça ou riqueza do candidato ou porque o matrimônio venha a ser homossexual em vez de heterossexual" (p. 98). Em suma, o conceito de desenvolvimento humano apresentado nesse texto pode ser defendido como valor básico, principal, primeiro e último por aqueles que não concordarem com a proposta de Skinner de que esse valor seria a sobrevivência das culturas.

Engajar-se em práticas culturais visando à sobrevivência das culturas é envolver-se com valores morais e políticos, o que pressupõe uma tarefa preliminar de formação do autocontrole. Cabe à sociedade, às comunidades, aos grupos sociais, à escola, à família e às pessoas tomarem a si a responsabilidade de formação das crianças e dos jovens nos valores éticos e políticos. Com efeito, são essas agências de controle e essas pessoas que ensinam os controles necessários para o desenvolvimento de valores, e é aí que, ao fim e ao cabo, as crianças e os jovens adquirem autocontrole e dessa maneira tornam-se preparados para enfrentar as tarefas relacionadas com a sobrevivência das culturas (Skinner, 1953, 1968, 1974)

Se uma educação para o autocontrole é fundamental para transitar da natureza à cultura e para a formação dos valores, qual seria a educação necessária para aprender a conviver com diferenças, para engajar-se na sobrevivência das culturas e no desenvolvimento humano como uma política de identidade? Aqui, parece que a educação deve visar à formação do indivíduo. E isso precisa ficar razoavelmente bem explicado para que não se confunda indivíduo com individualismo, porque, como já foi ressaltado, Skinner (1971) condena o individualismo. Serão apresentadas brevemente algumas considerações sobre a noção de indivíduo com o propósito exclusivo de tão somente indicar o local lógico desse conceito em uma prática cultural visando o desenvolvimento humano no contexto da crítica pós-moderna.

O indivíduo é constituído por uma história natural e outra cultural e, por isso, é tanto um organismo quanto uma pessoa (Skinner, 1971, 1974). Sua história cultural, que já lhe permite ultrapassar a condição de mero organismo, é também a condição que lhe possibilita ser aquilo que precisamente é, um indivíduo, ou seja, é nessa história que o organismo se transforma em pessoa, e a pessoa em indivíduo. Sobre isso vale citar um longo porém esclarecedor trecho de Skinner (1971): "Mesmo aqueles que se sobressaem como revolucionários são quase totalmente os produtos convencionais dos sistemas que derrubam. Eles falam a linguagem, usam a lógica e ciência, observam muitos dos princípios éticos e legais, e empregam as habilidades práticas e o conhecimento que a sociedade lhes deu. Uma pequena parte de seu comportamento pode ser até dramaticamente excepcional, e teremos que procurar por razões excepcionais em suas histórias idiossincráticas. Atribuir suas contribuições originais ...” (p. 124)

Em uma palavra, o indivíduo é uma pessoa original, seu comportamento caracteriza-se pela excepcionalidade oriunda de uma história idiossincrática. Sendo assim, formar indivíduos é formar pessoas criativas, é educar para a criatividade. Grosso modo, uma educação para a criatividade deve reconhecer a importância da diversidade e desenfatizar a similaridade e a reprodução. Isso significa programar condições de aprendizagem que aumentem a probabilidade da ocorrência de comportamentos originais, estimulando os acidentes e os "erros" e os "desvios" e as novidades e as inovações e as idiossincrasias com origem no comportamento do indivíduo (Skinner, 1968, 1974).

Em suma, educação para uma prática cultural visando ao desenvolvimento humano deveria se preocupar com a formação de indivíduos com capacidade de elaborar, respeitar e conviver com diferenças de identidade bem como com o suficiente autocontrole para inventar e por em funcionamento práticas culturais com condições de promover uma política de identidade pós-moderna. Nesse sentido, o psicólogo como profissional, e principalmente em suas relações face a face como cidadão, está condenado prioritariamente a ser um animal moral e político.

\section{Referências}

Abbagnano, N. (1982). Dicionário de filosofia (A. Bosi, Trad.). São Paulo: Mestre Jou (Original publicado em 1962)

Adorno, T. W. (1995). Educação e emancipação (W. L. Maar, Trad.). São Paulo: Paz e Terra. (Original publicado em 1971)

Aristóteles (1985a). Physics. Em J. Barnes (Org.), The complete works of Aristotle. (R. P. Hardie \& R. K. Gaye, Trads.) (pp. 315-446). Princenton, NJ: Princenton University Press. (Original publicado em s.d.)

Aristóteles (1985b). Nicomachean ethics. Em J. Barnes (Org.), The complet works of Aristotle (W. D. Ross, Trad.) (pp. 1729-1867). Princenton, NJ: Princeton University Press. (Original publicado em s.d.)

Bernstein, R. J. (1983). Beyond objectivism and relativism. Oxford: Basil Blackwell. Bruner, J. (1986). Actual minds, possible worlds. Cambridge: Harvard University Press.

Bruner, J. (1990). Acts of meaning. Cambridge: Harvard University Press. 
Dawkins, R. (1989). O gene egoísta (G. M. Florsheim, Trad.). São Paulo: Itatiaia. (Original publicado em 1976)

Frankena, W. L. (1963). Ethics. Englewood Cliffs: Prentice-Hall.

Garrett, R. (1979). Value conflict in a skinnerian analysis. Behaviorism, 7, 916.

Hall, S. (1998). A identidade cultural na pós-modernidade (T. T. da Silva \& G. L. Loura, Trads.). Rio de Janeiro: DP\&A. (Original publicado em 1992)

Hobbes, T. (1983). Leviatã (J. P. Monteiro \& M. B. N. da Silva, Trads.). São Paulo: Victor Civita. (Original publicado em 1651)

Lyotard, J-F (1987). O pós-moderno explicado às crianças (T. Coelho, Trad.). Lisboa: Publicações Dom Quixote. (Original publicado em 1986)

Lyotard, J-F (1998). A condição pós-moderna (R. C. Barbosa, Trad.). Rio de Janeiro: José Olympio. (Original publicado em 1979)

Platão (1985). Philebus. Em E. Hamilton \& H. Cairns (Orgs.), The collected dialogues of Plato (R. Hackforth, Trad.) (pp. 1086-1150). Princenton: Princeton University Press. (Original publicado em s.d.)

Polkinghorne, D. (1989). Changing conversations about human science. Em S. Kvale (Org.), Issues of validity in qualitative research (pp. 13-45). Lund: Studentlitteratur.

Rorty, R. (1980). Philosophy and the mirror of nature. Princeton: Princeton University Press.

Rorty, R. (1982). Consequences of pragmatism. Minneapolis: University of Minnesota Press.
Rorty, R (1997). ¿Esperanza o conocimiento? Una introducción al pragmatismo (E. Rabossi, Trad.). Buenos Aires: Fondo de Cultura Económica. (Original publicado em 1994)

Skinner, B. F. (1948). Walden two. New York: The Macmillan Company.

Skinner, B. F. (1953). Science and buman bebavior. New York: The Macmillan Company.

Skinner, B. F. (1968). The technology of teaching. New York: Meredith Corporation.

Skinner, B. F. (1969). Contingencies of reinforcement. New York: AppletonCentury-Crofts.

Skinner, B. F. (1971). Beyond freedom and dignity. New York: Alfred A. Knopf.

Skinner, B. F. (1974). About behaviorism. New York: Alfred A. Knopf.

Skinner, B. F. (1978). Reflections on behaviorism and society. Englewood Cliffs: Prentice-Hall.

Skinner, B. F. (1986). What is wrong with daily life in the Western World? American Psychologist, 41, 568-574.

Skinner, B. F. (1989). Recent issues in the analysis of behavior. Columbus: Merrill Publishing Company.

Skinner, B. F. (1990). Can psychology be a science of mind? American Psychologist, 45, 1206-1210.

Recebido em 15/06/2000

Revisado em 4/07/2000

Aceito em 4/07/2000

Sobre o autor:

José Antônio Damásio Abib é Psicólogo pela Universidade de Brasília, Mestre em Psicologia e Doutor em Ciências pela Universidade de São Paulo. Fez Pós-Doutorado em Epistemologia da Psicologia na Dinamarca (1989-1991). Atualmente é Professor do Departamento de Filosofia e Metodologia das Ciências da Universidade Federal de São Carlos-SP. 